\title{
Correlation between microvessel density (MVD) and multi-spiral CT (MSCT) perfusion parameters of esophageal cancer lesions and the diagnostic value of combined CtBP2 and P16 ${ }^{\text {INK4A }}$
}

\author{
Qinghua $\mathrm{Li}^{1 \#}$, Dong Cui ${ }^{2 \#}$, Yu Feng ${ }^{2}$, Yanfei He ${ }^{1}$, Zheng Shi ${ }^{1}$, Rui Yang ${ }^{1}$ \\ ${ }^{1}$ Department of Medical Imaging, Henan Provincial Chest Hospital, Zhengzhou, China; ${ }^{2}$ Department of Thoracic Surgery, Henan Provincial Chest \\ Hospital, Zhengzhou, China \\ Contributions: (I) Conception and design: Q Li, D Cui; (II) Administrative support: Q Li, D Cui; (III) Provision of study materials or patients: All \\ authors; (IV) Collection and assembly of data: All authors; (V) Data analysis and interpretation: All authors; (VI) Manuscript writing: All authors; (VII) \\ Final approval of manuscript: All authors. \\ \#These authors contributed equally to this work. \\ Correspondence to: Qinghua Li. Department of Medical Imaging, Henan Provincial Chest Hospital, No. 1, Weiwu Road, Zhengzhou 450003, China. \\ Email: liqinghuahnszl@sina.com.
}

Background: This article aims to analyze the correlation between microvessel density (MVD) and multispiral CT(MSCT) perfusion parameters of esophageal cancer lesions, and the diagnostic value of combining C-terminal binding protein 2 (CtBP2) and P16 inhibitor of cyclin-dependent kinase $4 \mathrm{a}\left(\mathrm{P} 16^{\mathrm{INK4A}}\right)$.

Methods: A total of 42 cases of normal esophageal mucosa tissues $>5 \mathrm{~cm}$ from the cancer tissue were selected as the control group. The expression levels of CtBP2 and P16 $6^{\mathrm{INK} 4 \mathrm{~A}}$ and the values of MSCT perfusion parameters and MVD were compared in the control group and esophageal cancer group. SP immunohistochemical staining was used to detect protein expression levels of CtBP2 and P16 ${ }^{\text {INK4A }}$. The Pearson method was used to analyze the differences and pertinence of MSCT perfusion parameters and MVD in the control group and esophageal cancer group. The receiver operating characteristic (ROC) curve was used to calculate the diagnostic value of CtBP2 and P16 ${ }^{\text {INK4A }}$ combined with MVD and MSCT perfusion parameters in esophageal cancer.

Results: The positive expression rate of $\mathrm{P} 16^{\mathrm{INK} 4 \mathrm{~A}}$ in the esophageal cancer group was significantly lower than that in the control group. The positive expression rates of CtBP2, blood volume (BV), mean transit time (MTT), surface permeability (permeability surface, PS), and MVD values were significantly higher than those of the control group $(\mathrm{P}<0.05)$. There was no significant difference in blood flow $(\mathrm{BF})$ value between the 2 groups $(\mathrm{P}>0.05)$. The $\mathrm{BF}$ value of the tumor invading the fibrous membrane was significantly higher than that of the non-invading fibrous membrane $(\mathrm{P}<0.05)$, and the PS and MVD values of the patients with lymph node metastasis were higher than those without lymph node metastasis $(\mathrm{P}<0.05)$. The MSCT perfusion parameters $\mathrm{BF}$ and $\mathrm{BV}$ were significantly positively correlated with MVD $(\mathrm{P}<0.05)$, while MTT, PS, and MVD were not significantly correlated $(\mathrm{P}>0.05)$. ROC results showed that the areas under curve (AUC) of CtBP2, P16 ${ }^{\mathrm{INK} 4 \mathrm{~A}}$, and MSCT were $0.625,0.747$, and 0.812 , respectively. However, the area under the combined detection curve was larger, at 0.869 .

Conclusions: MSCT perfusion imaging of esophageal cancer lesions can indirectly reflect the angiogenesis of esophageal cancer, and the combination of CtBP2 and P16 $6^{\mathrm{INK} 4 \mathrm{~A}}$ can effectively improve the diagnostic efficiency of the disease.

Keywords: Esophageal cancer; multi-spiral CT (MSCT); microvessel density (MVD); P16 inhibitor of cyclindependent kinase 4a $\left(\mathrm{P} 16^{\mathrm{INK} 4 \mathrm{~A}}\right)$; C-terminal binding protein 2 (CtBP2)

Submitted Mar 19, 2021. Accepted for publication May 26, 2021.

doi: 10.21037/jgo-21-247

View this article at: http://dx.doi.org/10.21037/jgo-21-247 


\section{Introduction}

Esophageal cancer is a malignant tumor that originates from the epithelium of the esophageal mucosa, accounting for $2 \%$ of all malignant tumors (1). The basis of tumor development and metastasis is closely related to tumor angiogenesis, the cell cycle negative regulator $\mathrm{P} 16^{\mathrm{INK} 4 \mathrm{~A}}$, and the transcription inhibitor C-terminal binding protein 2 (CtBP2) (2). Tumor microvessel density (MVD) is the "gold standard" that reflects tumor neovascularization, but the determination of MVD depends on living tissue. With the popularity of multi-spiral CT(MSCT), MSCT perfusion imaging has been widely used in a variety of organs and tumors, which can quantitatively reflect the characteristics of lesions or tumor microcirculation (3). High MVD is a prognostic factor among esophageal cancer that indicated worse prognosis in these patients (4). The abnormal expression and modification of CtBP2 and P16 inhibitor of cyclindependent kinase $4 \mathrm{a}\left(\mathrm{P} 16^{\mathrm{INK} 4 \mathrm{~A}}\right)$ play an important role in the occurrence of esophageal cancer. $\mathrm{CtBP} 2$, as a transcriptional corepressor of epithelial-specific genes, contributes to malignant development of human esophageal squamous cell carcinoma by regulation of $\mathrm{p} 16^{\mathrm{INK} 4 \mathrm{~A}}(5)$. Cyclin $\mathrm{H}(\mathrm{CCNH}) /$ cyclin-dependent kinase 7 (CDK7)-CtBP2 axis may augment ESCC cell migration (6). Aberrant methylation of p16INK4a and deletion of p15INK4b are frequent events in human esophageal cancer in Linxian, China (7). Previous studies have found that the expression of CtBP2 and $\mathrm{P} 16^{\mathrm{INK} 4 \mathrm{~A}}$ has certain differences in esophageal benign and malignant diseases, which is of great significance for disease diagnosis (8). However, there are few reports regarding $M V D$ and MSCT perfusion parameters combined with $\mathrm{CtBP} 2$ and $\mathrm{P} 16^{\mathrm{INK} 4 \mathrm{~A}}$ in the diagnosis of esophageal cancer. Therefore, this study aims to provide a reliable basis for clinical diagnosis and treatment by analyzing the diagnostic value between MVD and MSCT perfusion parameters combined with $\mathrm{CtBP} 2$ and $\mathrm{P} 16^{\mathrm{INK} 4 \mathrm{~A}}$ in esophageal cancer. We present the following article in accordance with the STARD reporting checklist (available at http://dx.doi.org/10.21037/jgo-21-247).

\section{Methods}

\section{General information}

The clinical data of 103 patients with esophageal cancer admitted to our hospital from January 2019 to January 2021 were collected. All patients agreed to participate in this study and signed an informed consent form. The study was conducted in accordance with the Declaration of Helsinki (as revised in 2013). This study was approved by the Henan Provincial Chest Hospital (No. 20181224). The inclusion criteria were as follows: (I) all patients met the relevant diagnostic criteria for esophageal cancer (9); (II) no history of allergies; (III) no history of esophageal cancer related radiotherapy and chemotherapy; (IV) no contraindications for CT examination. The exclusion criteria were as follows: (I) combined with any other tumor diagnosis history; (II) combined with immune function and blood dysfunction; (III) severe renal insufficiency; (IV) missing clinical data.

Finally, a total of 91 patients were enrolled, including 55 males and 36 females. The ages ranged from 44 to 65 years old, with an average of $57.69 \pm 8.14$ years old. In terms of pathological types, there were 17 cases of adenocarcinoma and 74 cases of squamous cell carcinoma. There were 62 cases of high-medium differentiation and 29 cases were poorly differentiated. In terms of clinical staging, there were 15 cases in stage I, 36 cases in stage II, and 40 cases in stage III, and 71 cases had lymph node metastasis. A total of 42 cases of normal esophageal mucosa tissues $>5 \mathrm{~cm}$ from the cancer tissue were selected as the control group. It was confirmed pathologically that there was no tumor cell infiltration, inflammation, cell proliferation, and other pathological changes.

\section{MSCT examination}

The American GE 64-row CT machine was employed to detect relevant indicators. During the scan, the patient needed to breathe calmly and never swallow. The scan range was from the entrance of the patient's neck thorax to the plane of the stomach fundus. The scanning parameters were tube voltage of $120 \mathrm{kV}$, tube current of $120 \mathrm{~mA}$, scanning layer thickness of $5 \mathrm{~mm}$, thread pitch of 1.0 , and reconstruction layer thickness of $2 \mathrm{~mm}$. The patient lay flat on the scanning bed in the supine position. A conventional plain scan $+50 \mathrm{~mL}$ iohexol enhanced scan was usually used, and the injection rate of cubital vein injection was $4 \mathrm{~mL} / \mathrm{s}$. After the scan was completed, the CT post-processing workstation was used to reconstruct the coronal and sagittal images of the patient's axial scan. Corresponding blood flow (BF) and blood volume (BV), mean transit time (MTT), and surface permeability (permeability surface, PS) were measured. Three areas were selected, then the perfusion related parameters and their average value were obtained. 
Table 1 Comparison of CtBP2 and P16 $6^{\mathrm{INK} 4 \mathrm{~A}}$ expression in the control group and esophageal cancer group

\begin{tabular}{|c|c|c|c|c|}
\hline Group & \multicolumn{2}{|c|}{ CtBP2, n (\%) } & \multicolumn{2}{|c|}{$\mathrm{P} 16^{\mathrm{INK} 4 \mathrm{~A}}, \mathrm{n}(\%)$} \\
\hline Esophageal cancer group $(n=91)$ & $51(56.04)$ & $40(43.96)$ & $23(25.27)$ & $68(74.73)$ \\
\hline Control group $(n=42)$ & $8(19.05)$ & $34(80.95)$ & $30(71.43)$ & $12(28.57)$ \\
\hline$\chi^{2}$ & \multicolumn{2}{|c|}{15.936} & \multicolumn{2}{|c|}{25.538} \\
\hline
\end{tabular}

CtBP2, C-terminal binding protein 2; P16 ${ }^{\text {INK4A }}, \mathrm{P} 16$ inhibitor of cyclin-dependent kinase 4a; P value, probability; $\chi^{2}$-test, Chi-square test.

\section{CtBP2 and P1 ${ }^{I N K 4 A}$ detection}

The main reagents included mouse anti-human CtBP2 monoclonal antibody (U.S. Neomarkers company) and rabbit anti-human $\mathrm{P} 16^{\mathrm{INK} 4 \mathrm{~A}}$ polyclonal antibody (Wuhan Boster Biotechnology Co., Ltd., China). The streptavidin-peroxidase ligation (SP) kit, trypsin, and the diaminobenzidine substrate color kit were purchased from Fuzhou Maixin Company.

The esophageal cancer tissue was fixed with $4 \%$ paraformaldehyde for $24 \mathrm{~h}$, embedded in paraffin, and sectioned. Paraffin sections were separated in xylene and rehydrated in gradient ethanol. According to the instructions, SP immunohistochemical staining was used to detect protein expression levels of CtBP2 and P16 $6^{\mathrm{INK} 4 \mathrm{~A}}$. The negative control of the primary antibody was replaced by phosphate buffered saline (PBS).

The results were judged based on the percentage of positive cells and the intensity of staining (10). (I) The positive standard was the bleeding of brown or brown particles in the nucleus or cytoplasm. Zero points were for colorless, 1 point for grayish yellow, 2 points for golden yellow, and 3 points for brown. The total score was the product of the above 2 scores. A positive meant that the total score was $>4$ points. (II) The positive cell rate calculation involved the random selection of 5 high-power fields from each slice and calculating the number of positive cells. Positive cell rate $=$ positive cell number/observed cell number $\times 100 \%$. Zero points indicated no positive cells, 1 point indicated positive cells $<10 \%, 2$ points was $10-50 \%, 3$ points was $50-75 \%$, and 4 points was $>75 \%$. The total score was the product of the above 2 scores. A positive meant that the total score was $>4$ points.

\section{MVD count}

Low-power microscopy $(\times 100)$ was used to observe the SP-stained sections. The most stained vascular endothelial cells were selected in the field of view. High-power microscopy $(\times 400)$ was used to count the number of microvessels in the 3 fields, and then the average value was taken as the MVD value.

\section{Observation indicators}

(I) The expression levels of CtBP2 and P16 ${ }^{\mathrm{INK} 4 \mathrm{~A}}$, MSCT perfusion parameters, and MVD were compared in the control group and the esophageal cancer group. (II) The different pathological characteristics and the correlation between MSCT perfusion parameters and MVD were analyzed. (III) The diagnostic value of CtBP2 and $\mathrm{P} 16^{\text {INK4A }}$ combined with MSCT in esophageal cancer.

\section{Statistical analysis}

The data in this study were statistically analyzed using SPSS18.0 software. The measurement data were described by the mean \pm standard deviation. The $t$ test was used to express the pass rate or composition ratio of the count data, and the $\chi^{2}$ test was used. Correlation analysis was performed using Pearson's method, and a scatter plot was generated. The receiver operating characteristic (ROC) curve was used to analyze the diagnostic value of $\mathrm{CtBP} 2$ and $\mathrm{P} 16^{\mathrm{INK} 4 \mathrm{~A}}$ combined with MSCT perfusion parameters and MVD in esophageal cancer. The difference was statistically significant at $\mathrm{P}<0.05$ and the test level was $\alpha=0.05$.

\section{Results}

\section{Comparison of $C t B P 2$ and $P 16^{\wedge} I N K 4 A$ expression in the control group and the esophageal cancer group}

As shown in Table 1 and Figure 1, the positive expression rate of $\mathrm{P} 16^{\mathrm{INK} 4 \mathrm{~A}}$ in the esophageal cancer group was 


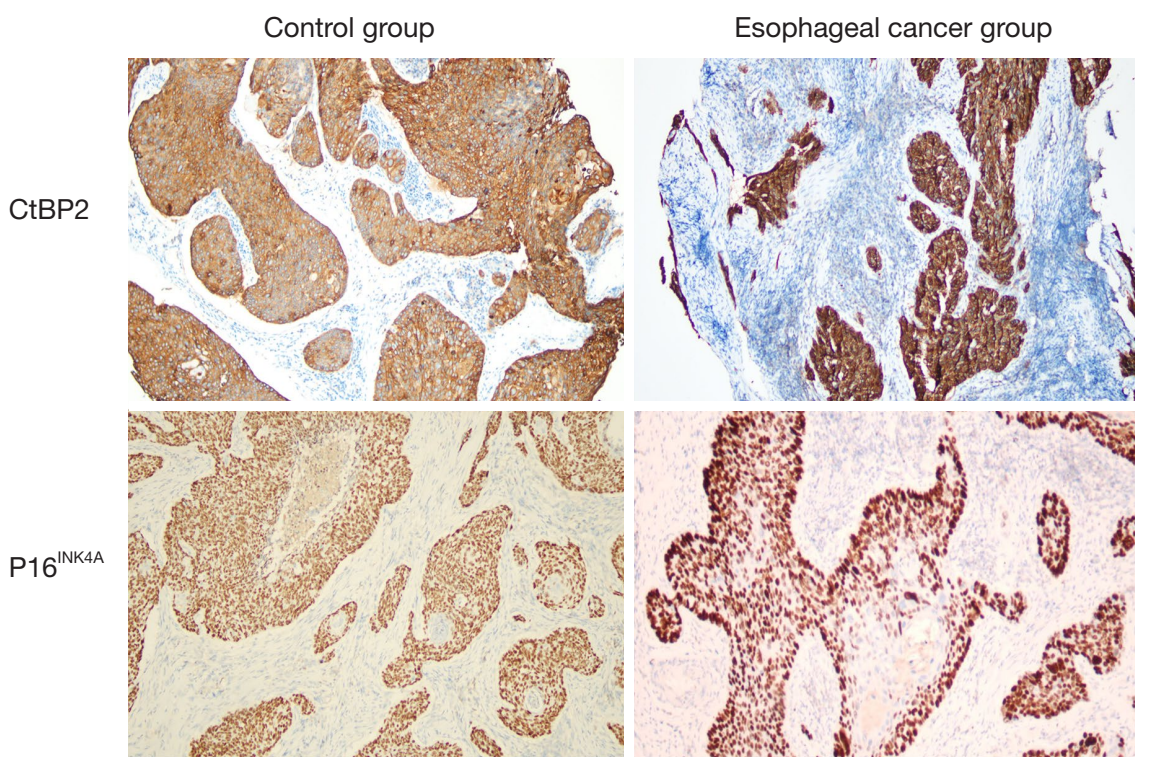

Figure $1 \mathrm{CtBP} 2$ and $\mathrm{P} 16^{\mathrm{INK} 4 \mathrm{~A}}$ immunohistochemical detection $(\times 200)$.

Table 2 Comparison of CtBP2 and $\mathrm{P} 16^{\mathrm{INK} 4 \mathrm{~A}}$ expression in the control group and esophageal cancer group

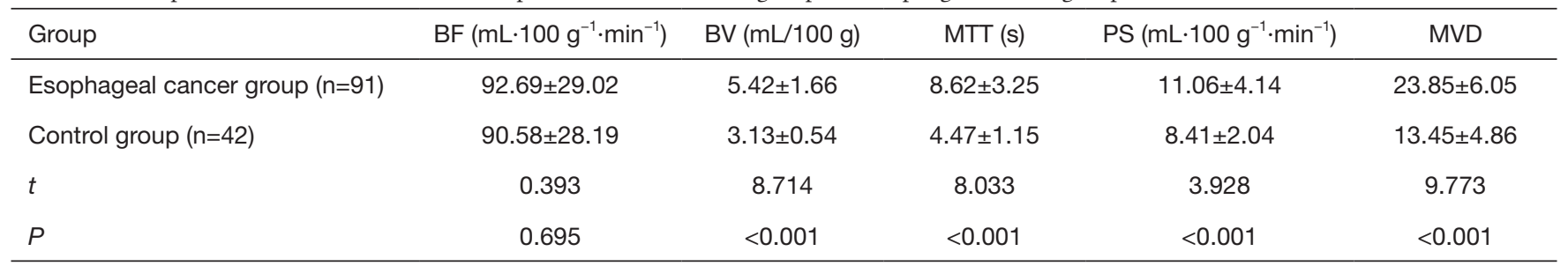

CtBP2, C-terminal binding protein 2; P16 ${ }^{\text {INK4A }}, \mathrm{P} 16$ inhibitor of cyclin-dependent kinase 4a; BF, blood flow; BV, blood volume; MTT, mean transit time; MVD, microvessel density; PS, permeability surface; $\mathrm{P}$ value, Probability; $t$-test, Student's $t$ test.

significantly lower than that of the control group, while the positive expression rate of $\mathrm{CtBP} 2$ in the esophageal cancer group was higher than that of the control group $(\mathrm{P}<0.05)$.

\section{Comparison of CT perfusion parameter values and MVD in the control group and the esophageal cancer group}

As shown in Table 2, the values of BV, MTT, PS, and MVD in the esophageal cancer group were increased compared with the control group $(\mathrm{P}<0.05)$. There was no significant difference in $\mathrm{BF}$ values between the 2 groups $(\mathrm{P}>0.05)$.

\section{Comparison of MSCT perfusion parameters and MVD in patients with different pathological characteristics}

As shown in Table 3, the BF value of the tumor invading the fibrous membrane was significantly higher than that of the tumor not invading the fibrous membrane $(\mathrm{P}<0.05)$. The PS and MVD values of patients with lymph node metastasis were higher than those without lymph node metastasis $(\mathrm{P}<0.05)$. There were no significant differences in different pathological types, degree of differentiation, and clinical stages for MSCT perfusion parameters and MVD $(\mathrm{P}>0.05)$.

\section{Correlation analysis of MSCT perfusion parameters and MVD}

As shown in Table 4 and Figure 2, MSCT perfusion parameters $\mathrm{BF}$ and $\mathrm{BV}$ were significantly positively correlated with MVD $(\mathrm{P}<0.05)$, while MTT, PS, and MVD were not significantly correlated with MVD $(\mathrm{P}>0.05)$. 


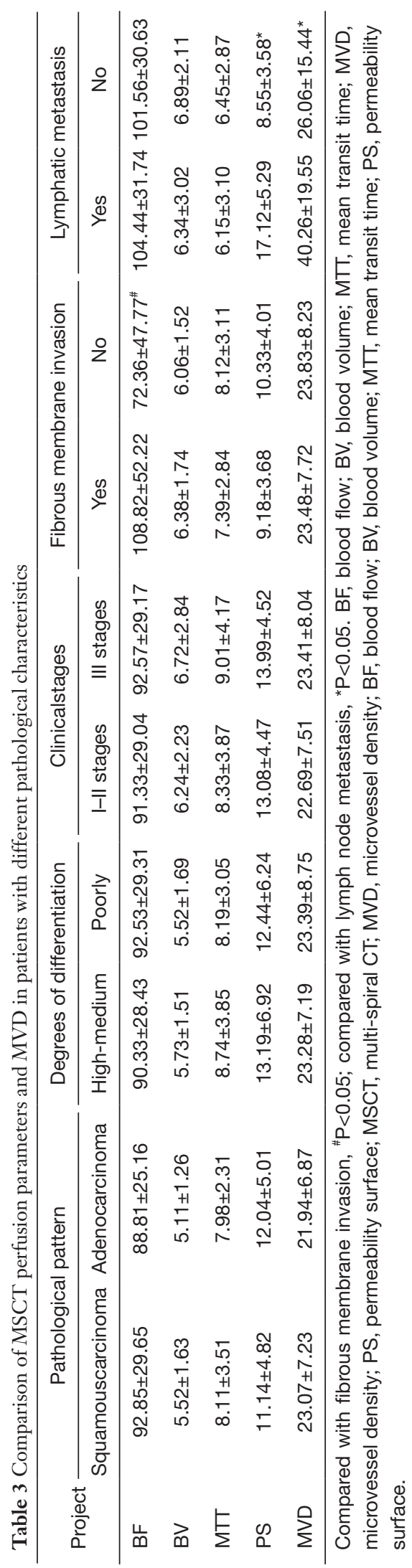

Table 4 Correlation analysis of MSCT perfusion parameters and MVD

\begin{tabular}{lcc}
\hline \multirow{2}{*}{ MSCT perfusion parameter } & \multicolumn{2}{c}{ MVD } \\
\cline { 2 - 3 } & $r$ value & $P$ value \\
\hline BF & 0.447 & 0.025 \\
BV & 0.567 & 0.003 \\
MTT & -0.189 & 0.125 \\
PS & 0.201 & 0.094 \\
\hline
\end{tabular}

MSCT, multi-spiral CT; MVD, microvessel density; BF, blood flow; BV, blood volume; MTT, mean transit time; PS, permeability surface. $\mathrm{P}$ value, Probability; $r$ value, right value.

\section{The diagnostic value of $\mathrm{CtBP2}$ and P16 ${ }^{\mathrm{INK4A}}$ combined with MSCT in esophageal cancer}

As shown in Table 5 and Figure 3, ROC results showed that the areas under the curve (AUC) of CtBP2, P16 ${ }^{\mathrm{INK} 4 \mathrm{~A}}$, and MSCT were $0.625,0.747$, and 0.812 , respectively. However, the area under the combined test curve was the largest, at 0.869 .

\section{Case analysis}

A 66-year-old male patient had progressive dysphagia for 3 months. Upper gastrointestinal angiography showed stenosis, stiffness, and mucosal disorder in the middle part of the esophagus. The upper esophagus was slightly dilated (Figure 4A,B,C). The CT plain scan showed that the middle part of the thoracic segment of the esophagus was thickened and the lumen was narrowed (Figure $4 D, E$ ), and the enhanced scan showed obvious continuous enhancement (Figure 4F,G). The pathology showed squamous cell carcinoma, moderate chronic inflammation of the gastric antrum mucosa, and mild acute activity (Figure 4H,I).

\section{Discussion}

Esophageal cancer is a common malignant tumor of the digestive tract and has a high mortality rate. Due to the specific morphology of esophageal cancer, early detection is difficult, and most patients are in the middle and advanced stages of treatment (11). X-ray barium meal and CT examination are currently common methods for clinical diagnosis and efficacy evaluation. These examinations are limited due to their morbidity and indirect signs. Diagnosis still relies on endoscopic biopsy and ultrasound endoscopy, while MRI and radionuclide scanning only play 

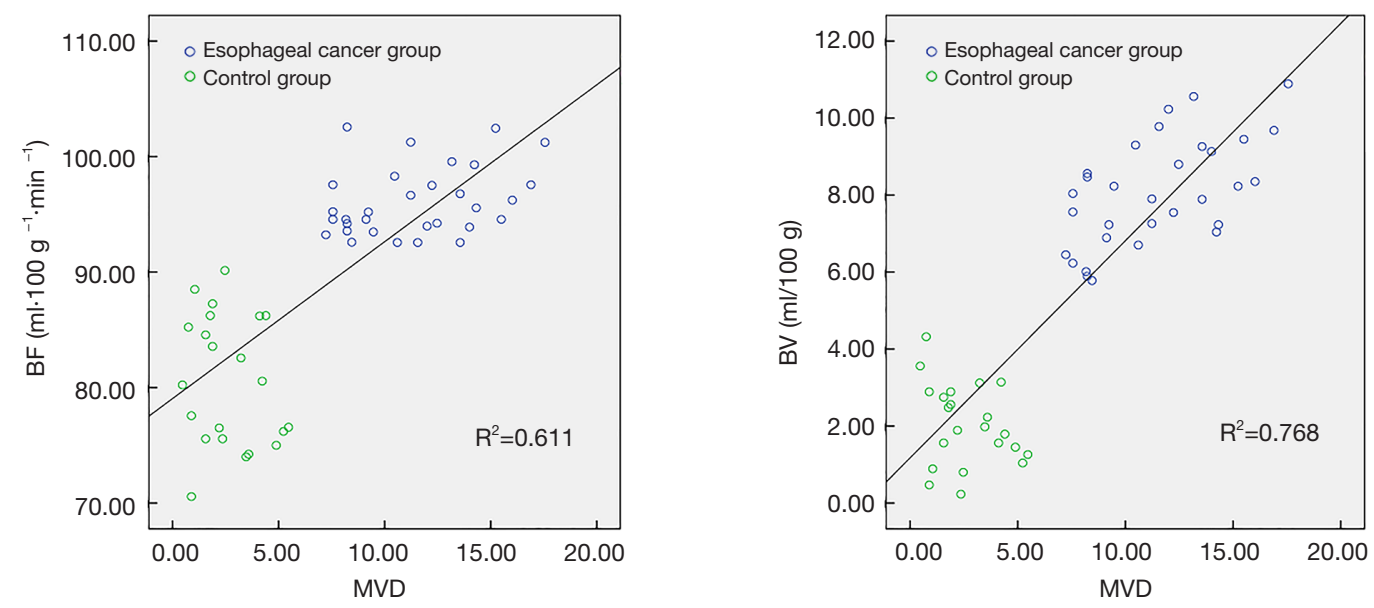

Figure 2 Correlation analysis.

Table 5 The diagnostic value of CtBP2 and P16 ${ }^{\text {INK4A }}$ combined with MSCT in esophageal cancer

\begin{tabular}{lcccc}
\hline Predictivefactor & Sensitivity & Specificity & AUC & 95\% Cl \\
\hline MSCT & 0.718 & 0.694 & 0.812 & $0.688-0.936$ \\
CtBP2 & 0.535 & 0.723 & 0.625 & $0.463-0.787$ \\
P16 & $0.6684 \mathrm{~A}$ & 0.736 & 0.747 & $0.615-0.879$ \\
MSCT + CtBP2 + P16 & 0.952 & 0.885 & 0.869 & $0.766-0.972$ \\
\hline
\end{tabular}

CtBP2, C-terminal binding protein 2; P16 ${ }^{\text {INK } 4 \mathrm{~A}}, \mathrm{P} 16$ inhibitor of cyclin-dependent kinase 4a; MSCT, multi-spiral CT; Cl, confidence interval.

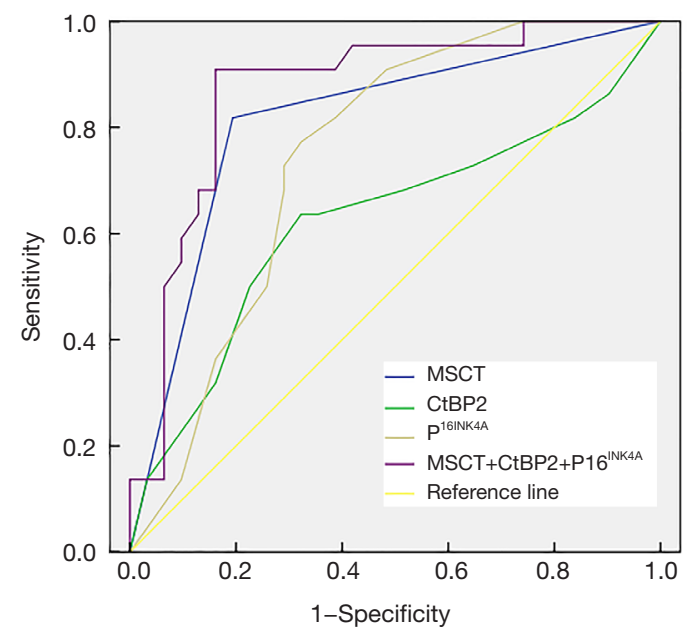

Figure 3 Receiver operating characteristic (ROC) curve analysis of C-terminal binding protein $2(\mathrm{CtBP} 2)$ and $\mathrm{P} 16$ inhibitor of cyclindependent kinase $4 \mathrm{a}\left(\mathrm{P} 16^{\mathrm{INK} 4 \mathrm{~A}}\right)$ combined with multi-spiral CT (MSCT) in esophageal cancer. supplementary roles in its diagnosis. However, none of them can directly display the tumor blood supply and tumor angiogenesis (12).

CT perfusion imaging technology is a non-invasive functional imaging technique which can perform dynamic same-layer scanning of the lesion through contrast agent perfusion, obtain the time-density curve (TDC) of each pixel, and calculate the perfusion parameter values, such as BF, BV, MTT, PS, etc. (13). The blood perfusion status of the lesion can be directly evaluated based on the value of these perfusion parameters to reflect its development. At the same time, it can also judge the MVD and then evaluate the activity, pathological grade, and prognosis of the tumor (14). Tumor angiogenesis is the basic process of its growth and metastasis, and it is the physiological basis for tumor proliferation, nutrition supply, and metabolite elimination. Peripheral lung cancers with different histological types have different angiogenesis methods and numbers (15). In this study, statistical analysis found that there were no 

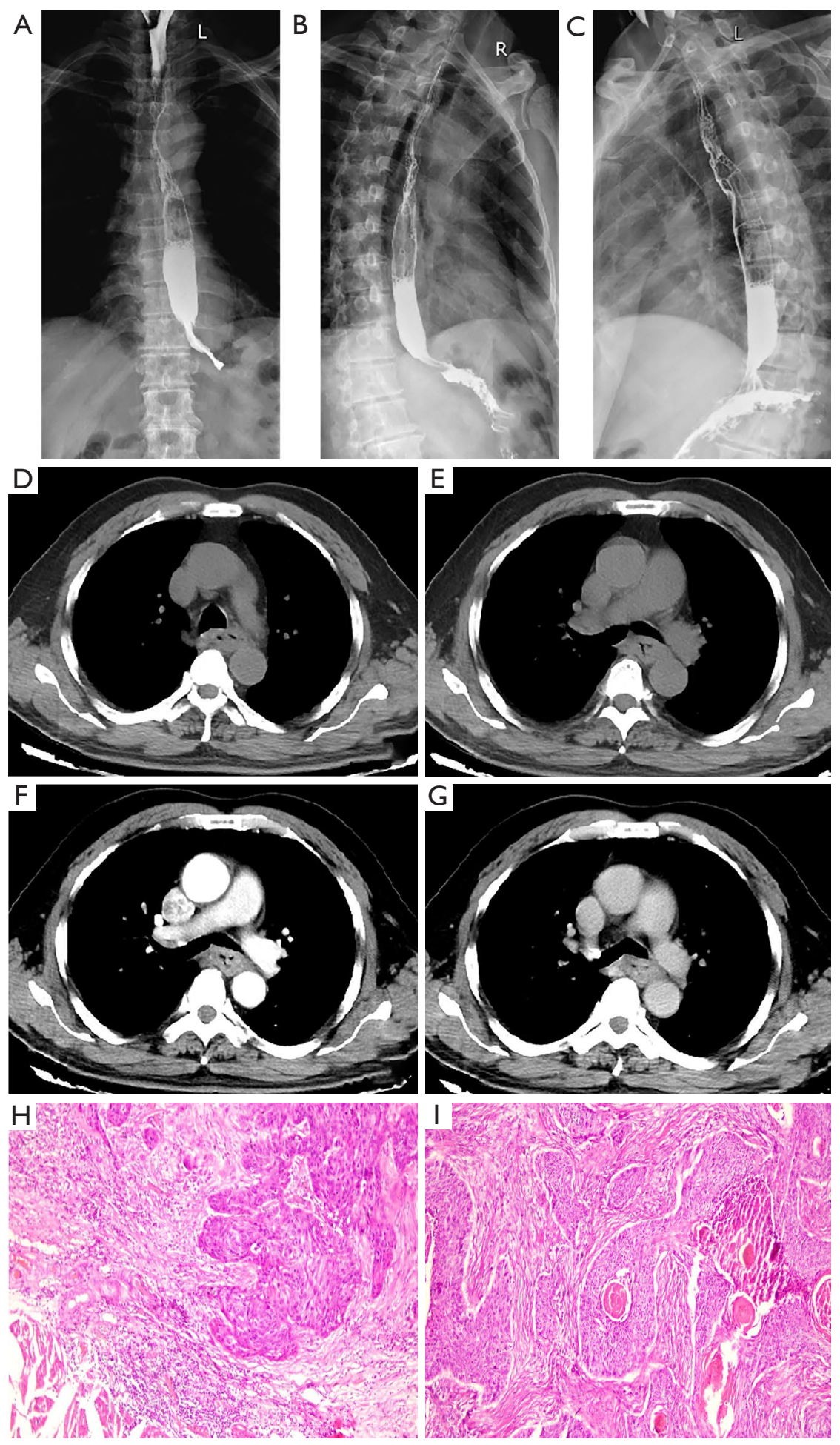

Figure 4 Case analysis. The patient, a 66-year-old male, had progressive dysphagia for 3 months. The upper gastrointestinal angiography showed that the middle part of the esophagus was narrow and rigid, and the mucous membrane was disordered. The upper esophagus was slightly dilated $(\mathrm{A}, \mathrm{B}, \mathrm{C})$. CT plain scan showed local tube wall thickening and lumen stenosis in the middle of the thoracic segment of the esophagus (D,E), enhanced scan showed obvious continuous enhancement (F,G). Pathology showed: squamous cell carcinoma 22-27 cm from the incisors of the esophagus, moderate chronic inflammation of the gastric antral mucosa (H,I, HE staining, 400x). 
significant differences in CT perfusion parameters and MVD measurements of esophageal cancer with different differentiation levels and pathological types, which was consistent with some foreign literature reports. Tumor growth is mainly supported by new blood vessels with nutrients, which is the pathological basis for tumor cell metastasis and invasion, accounting for approximately $1-10 \%$ of the tumor volume (16). According to the definition, $\mathrm{BF}$ is mainly determined by the characteristics of tumor $\mathrm{BF}$ and the density of microvessels inside the tumor, which reflects the BF in the local area. BV changes mainly depend on the diameter of blood vessels, the number of open capillaries, and also the number of capillaries. It is generally believed that MVD is the gold standard for evaluating BV. The results of this study found that MVD is positively correlated with $\mathrm{BF}$ and $\mathrm{BV}$, which is consistent with the report of Boothello et al. (17), further confirming the reliability of the above indicators for evaluating tumor angiogenesis.

Related foreign reports have found that molecular biology is also one of the more active research fields in addition to CT perfusion imaging, and it also plays an important role in the process of disease diagnosis and efficacy evaluation (18). $\mathrm{P} 16^{\mathrm{INK} 4 \mathrm{~A}}$ is an important gene that regulates the cell cycle and inhibits cell division. This gene can also induce cell apoptosis and is inactivated in approximately $50 \%$ of human tumors, among which familial melanoma and cholangiomas are related to mutations in the $\mathrm{P} 16^{\mathrm{INK4A}}$ gene (19). According to related reports, many other malignant tumors also have deletions and mutations of $\mathrm{P} 16^{\mathrm{INK} 4 \mathrm{~A}}$ (20). Rajendra et al. (21) reported that $\mathrm{P} 16^{\mathrm{INK} 4 \mathrm{~A}}$ was under-expressed in most esophageal cancer tissues, leading to cell cycle disorders and excessive cell proliferation. In this study, the positive expression rate of $\mathrm{P} 16^{\mathrm{INK} 4 \mathrm{~A}}$ in esophageal cancer tissue was significantly lower than that in control group, which was consistent with the above-mentioned literature reports.

CtBP2 is an important member of the CtBP family and plays an important role in embryonic development, adipogenesis, and angiogenesis. In recent years, many studies have found that CtBP2 is closely related to tumors (22). In colon cancer, breast cancer, and prostate cancer, CtBP2 can promote tumor proliferation and cell migration through various signaling pathways. In this study, the positive expression rate of CtBP2 in the esophageal cancer group was significantly higher than that of normal esophageal mucosa, suggesting that $\mathrm{CtBP} 2$ may be involved in the occurrence and development of esophageal cancer. At present, a large number of foreign studies have shown that the sensitivity and specificity of a single test cannot be used to qualitatively diagnose malignant tumors. The main reason is that tumor cells and normal tissues can express certain genes (23). Studies have suggested that the combined detection of imaging and molecular biology can improve the diagnosis of malignant diseases, but there is no final conclusion (24). In order to effectively avoid the above-mentioned diagnosis limitations, clinicians often advocate for the combination of multiple methods to improve the accuracy of disease diagnosis. This group of studies combined CtBP2, P16 ${ }^{\mathrm{INK} 4 \mathrm{~A}}$, and MSCT for the diagnosis of esophageal cancer cases. ROC curve analysis results showed that the AUC of combined diagnosis was significantly higher than that of single detection, which suggested that the combination of CtBP2, P16 ${ }^{\mathrm{INK} 4 \mathrm{~A}}$, and MSCT could effectively improve esophageal disease diagnosis. The reason may be that MSCT, CtBP2, and P1 $6^{\mathrm{INK4A}}$ can provide a dual basis for imaging and biochemical indicators for the clinical diagnosis of esophageal cancer, which makes the diagnosis evidence more sufficient, and makes up for the deficiency of single diagnosis and improves the accuracy of clinical diagnosis. However, this study has not yet compared the combined diagnostic value of the 2 indicators, and expansion of the sample size is needed for further discussion. In summary, MSCT perfusion imaging of esophageal cancer lesions can indirectly reflect the angiogenesis of esophageal cancer in vivo, and the combination of CtBP2 and $\mathrm{P} 16^{\mathrm{INK} 4 \mathrm{~A}}$ can effectively improve the diagnostic efficiency of the disease.

\section{Acknowledgments}

Funding: Medical science and technology project of Henan Province (NO. LHGJ20190740).

\section{Footnote}

Reporting Checklist: The authors have completed the STARD reporting checklist. Available at http://dx.doi.org/10.21037/ jgo-21-247

Data Sharing Statement: Available at http://dx.doi. org/10.21037/jgo-21-247

Conflicts of Interest: All authors have completed the ICMJE uniform disclosure form (available at http://dx.doi. org/10.21037/jgo-21-247). The authors have no conflicts of interest to declare. 
Ethical Statement: The authors are accountable for all aspects of the work in ensuring that questions related to the accuracy or integrity of any part of the work are appropriately investigated and resolved. All patients agreed to participate in this study and signed an informed consent form. The study was conducted in accordance with the Declaration of Helsinki (as revised in 2013). This study was approved by the Henan Provincial Chest Hospital (No. 20181224).

Open Access Statement: This is an Open Access article distributed in accordance with the Creative Commons Attribution-NonCommercial-NoDerivs 4.0 International License (CC BY-NC-ND 4.0), which permits the noncommercial replication and distribution of the article with the strict proviso that no changes or edits are made and the original work is properly cited (including links to both the formal publication through the relevant DOI and the license). See: https://creativecommons.org/licenses/by-nc-nd/4.0/.

\section{References}

1. Lee KD, Wang TY, Lu CH, et al. The bidirectional association between oral cancer and esophageal cancer: A population-based study in Taiwan over a 28 -year period. Oncotarget 2017;8:44567-78.

2. van der Horst S, Weijs TJ, Ruurda JP, et al. Robot-assisted minimally invasive thoraco-laparoscopic esophagectomy for esophageal cancer in the upper mediastinum. J Thorac Dis 2017;9:S834-42.

3. DaVee T, Ajani JA, Lee JH. Is endoscopic ultrasound examination necessary in the management of esophageal cancer? World J Gastroenterol 2017;23:751-62.

4. Ma G, Zhang J, Jiang $\mathrm{H}$, et al. Microvessel density as a prognostic factor in esophageal squamous cell cancer patients: A meta-analysis. Medicine 2017;96:e7600.

5. Guan C, Shi H, Wang H, et al. CtBP2 contributes to malignant development of human esophageal squamous cell carcinoma by regulation of p16INK4A. J Cell Biochem 2013;114:1343-54.

6. Zhang J, Zhu J, Yang L, et al. Interaction with CCNH/ CDK7 facilitates CtBP2 promoting esophageal squamous cell carcinoma (ESCC) metastasis via upregulating epithelial-mesenchymal transition (EMT) progression. Tumour Biol 2015;36:6701-14.

7. Xing EP, Nie Y, Wang LD, et al. Aberrant methylation of p16INK4a and deletion of p15INK4b are frequent events in human esophageal cancer in Linxian, China.
Carcinogenesis 1999;20:77-84.

8. Jankowski J, Caestecker JD, Love S, et al. Chemoprevention of esophageal cancer with esomeprazole and aspirin therapy: Efficacy and safety in the phase III randomized factorial ASPECT trial. J Clin Oncol 2018;36:LBA4008.

9. Su HA, Hsiao SW, Hsu YC, et al. Superiority of NBI endoscopy to PET/CT scan in detecting esophageal cancer among head and neck cancer patients: a retrospective cohort analysis. BMC Cancer 2020;20:69.

10. Zopfs D, GroßeHokamp N, Reimer R, et al. Value of spectral detector CT for pretherapeutic, locoregional assessment of esophageal cancer. Eur J Radiol 2021;134:109423.

11. Voncken FEM, Aleman BMP, van Dieren JM, et al. Radiation-induced liver injury mimicking liver metastases on FDG-PET-CT after chemoradiotherapy for esophageal cancer: A retrospective study and literature review. Strahlenther Onkol 2018;194:156-63.

12. Goense L, Heethuis SE, van Rossum PSN, et al. Correlation between functional imaging markers derived from diffusion-weighted MRI and 18F-FDG PET/CT in esophageal cancer. Nucl Med Commun 2018;39:60-7.

13. Smit JK, Muijs CT, Burgerhof JG, et al. Survival after definitive (chemo)radiotherapy in esophageal cancer patients: a population-based study in the north-East Netherlands. Ann Surg Oncol 2013;20:1985-92.

14. Hayrapetian A, Girgis MD, Yanagawa J, et al. Incidental Detection of Elastofibroma Dorsi With 68Ga-FAPI-46 and 18F-FDG PET/CT in a Patient With Esophageal Cancer. Clin Nucl Med 2021;46:e86-7.

15. Lee HN, Kim JI, Shin SY, et al. Combined CT texture analysis and nodal axial ratio for detection of nodal metastasis in esophageal cancer. Br J Radiol 2020;93:20190827.

16. Jecrois AM, Dcona MM, Deng X, et al. Cryo-EM structure of $\mathrm{CtBP} 2$ confirms tetrameric architecture. Structure 2021;29:310-319.e5.

17. Boothello RS, Patel NJ, Damle PK, et al. Abstract 3460: p38-p14ARF-CtBP2 axis as a novel regulator of CSC phenotype and tumor cell dormancy. Cancer Res 2018;78:3460.

18. Bellesis AG, Jecrois AM, Hayes JA, et al. Assembly of human C-terminal binding protein (CtBP) into tetramers. J Biol Chem 2018;293:9101-12.

19. Aftab A, Shahzad S, Hussain HMJ, et al. CDKN2A/ $\mathrm{P} 16 \mathrm{INK} 4 \mathrm{~A}$ variants association with breast cancer and their in-silico analysis. Breast Cancer 2019;26:11-28. 
20. Saadallah-Kallel A, Abdelmaksoud-Dammak R, Triki M, et al. Clinical and prognosis value of the CIMP status combined with MLH1 or p16 INK4a methylation in colorectal cancer. Med Oncol 2017;34:147.

21. Rajendra S, Yang T, Xuan W, et al. Active human papillomavirus involvement in Barrett's dysplasia and oesophageal adenocarcinoma is characterized by wild-type p53 and aberrations of the retinoblastoma protein pathway. Int J Cancer 2017;141:2037-49.

22. Geßner AL, Borkowetz A, Baier M, et al. Detection of HPV16 in Esophageal Cancer in a High-Incidence Region of Malawi. Int J Mol Sci 2018;19:557.

23. Wagner S, Prigge ES, Wuerdemann N, et al. Evaluation of p16INK4a expression as a single marker to select patients with HPV-driven oropharyngeal cancers for treatment deescalation. Br J Cancer 2020;123:1114-22.

24. Urbute A, Rasmussen CL, Belmonte F, et al. Prognostic Significance of HPV DNA and p16INK4a in Anal Cancer: A Systematic Review and Meta-Analysis. Cancer Epidemiol Biomarkers Prev 2020;29:703-10.

(English Language Editor: C. Betlazar-Maseh)
Cite this article as: Li Q, Cui D, Feng Y, He Y, Shi Z, Yang R. Correlation between microvessel density (MVD) and multispiral CT (MSCT) perfusion parameters of esophageal cancer lesions and the diagnostic value of combined CtBP2 and P16 ${ }^{\mathrm{INK} 4 \mathrm{~A}}$. J Gastrointest Oncol 2021;12(3):981-990. doi: 10.21037/ jgo-21-247 